\title{
Concerns for International Graduate Students in Political Science
}

How do you choose which universities to apply for? How do you navigate political science departmental norms and expectations? What are your job prospects as an international student in the U.S? These are a handful of questions that countless international political science graduate students prospective, pre-candidacy, and post-candidacy - will need to consider at some point. There may also be language, cultural, and financial barriers to achieving a graduate degree in political science. Thus, this chapter is designed to provide helpful information to navigate these concerns.

Although research on international students in the U.S. academic institutions has expanded in the last 20 years, it continues to remain somewhat scarce. The prevailing focus has been on undergraduate students (Arafeh 2020), specific groups of students (e.g., Chinese students) (Ma 2020), or on retention rates (Haverila, Haverila, and McLaughlin 2020). Unfortunately, existing studies have hardly addressed what support available for international students, especially for international political science graduate students. Given this, this chapter also seeks to provide ample advice.

\section{Why is this important?}

The journey as an international political science graduate student is not without obstacles and challenges. Across all disciplines, there are "language barriers, loneliness and homesickness, identity issues, changes in eating habits ... and financial setbacks," in addition to potential issues of racism and discrimination (Gautam et al. 2016, 503). Language barriers can also increase "academic stress, negative well-being, and feelings of isolation" (Gautam et al. 2016, 506; Stegall 2021, 725). Given these challenges, it is crucial for prospective students to identify universities to apply for that not only have courses in political science that interest them to sustain their passion, but also feature an office for international students and events that are dedicated to international students to help negate potential isolation and loneliness.

Further, interaction between international students and American students both inside and outside the classroom is also important because they can enhance understanding and knowledge of cultural disparities. In the U.S., there is an emphasis on "individualism, assertiveness, and selfsufficiency over interdependence and relatedness" (Gautam et al. 2016, 506); thus, knowing how to navigate this terrain can be helpful to prospective students. And whilst being a graduate student in the U.S. can improve career prospects, there will be challenges throughout the course of graduate programs, such as language barriers, cultural idiosyncrasies, and alternative views on assignments and work-life balance - all of which will likely be compounded by financial, social, and religious aspects (Gautam et al. 2016, 520-521). Additionally, interactions between students from different cultures can enrich relationships and foster academic perspectives that are more nuanced. Therefore, for both international and U.S. graduate students, the experiences can be challenging and enriching in cultural, economic, and career dimensions.

\section{Advice for international graduate students in political science}

\section{Application advice}

For prospective students, you must navigate the application process, visa and immigration protocols, complete - in some cases - the Graduate Record Examination (GRE), and identify opportunities for on-campus employment (e.g., teaching and research assistantships) and housing with nearby amenities. In considering which universities to apply for, understand that prestige of the institution matters for post-graduate program employment prospects, especially if intending to remain in the U.S., but give equal consideration to other aspects. For example, are the courses offered in the political science graduate program a good reflection of your own interests? Does the university have an office of international students that hosts social events? What are the costs of living? Are you eligible for a teaching and/or research assistantship, in addition to receiving funding for your tuition? 
If you do not find answers to these questions, consider contacting the graduate program director, graduate director, or administrative staff in the political science department.

One of the biggest concerns for international students is the lack of appropriate matching with an academic adviser (Krsmanovic 2021). Having a clear career plan before and during the application process will help you considerably. Therefore, it is important to conduct research about the political science graduate programs available and the faculty you believe you would be interested in collaborating with, as well as your desired academic adviser who will be able to guide you through the norms of U.S. graduate education.

\section{Financial advice}

Graduate school can be expensive, especially if you are paying for your own tuition. Consider other costs as part of the application process - GRE preparation and sitting the exam itself, university application costs, and visa and immigration processing fees. If English is not your native language, you will also need to present proof of proficiency in English (e.g., TOEFL, IELTS). Your capacity to work off-campus, if not employed by the university, is severely restricted in your first year (less so thereafter, but still very challenging) due to immigration and contractual limitations (often limited to working 20 hours per week during semester).

\section{Immigration and visa advice}

F-1 visas are the most significant as these are student visas for international graduate students. There are also J-1 visas for participants in educational and cultural exchange programs, but these are much fewer in number. There are other types of visas (M-1, F-3, M-3), but if you are applying to a graduate school in the U.S., you will need an F-1 visa. In terms of process, you will need to apply for the F-1 visa after securing a place at an SEVP-approved (Student and Exchange Visitor Program), accredited U.S. university. You will need to demonstrate you have sufficient funds to come and study in the U.S. - a letter from the University outlining their coverage of your tuition fees and providing you with an assistantship or fellowship is usually sufficient. Your invitation from the university to participate in their political science graduate program should outline any offer for tuition coverage, assistantships, or fellowships, and the duration for which they will provide funding.

In your visit to the U.S. embassy or consulate in your home country - or in a neighbouring country if your home country does not have one - you will need to bring the aforementioned documents (applications for F-1 visas will outline what documents are required). You will have an interview for the visa that will generally query about your available funds, why you are interested in studying in the U.S., and what you will be studying and where. As part of this process, you will need to familiarize yourself with I-20 forms, and SEVIS (Student and Exchange Visitor Information System) registration, the latter of which costs. Once all of this has been secured, you can arrange your travel plans and search for housing. You must also bear in mind that you may need to arrive in the summer - if the semester begins at the end of August or early September - for summer orientation programming for international students. This may involve further English language tests, teaching practice, social events, and learning about U.S. cultural norms. In your spare time, you should prepare yourself for what will likely be a culture shock and understand how U.S. culture differs from your own - how people dress, interact, shop, learn, teach, and talk (Filonova and Barriga 2020).

\section{Housing advice}

If possible, it is ideal for first-year international graduate students to secure on-campus accommodation as living off-campus without access to a vehicle can potentially lead to difficulties in commuting and navigating an unfamiliar setting. As part of this process, assess whether your desired university has a "dependable public transportation system" and that you can reside somewhere within reasonable distance of campus and amenities (e.g., access to food) (Gautam et al. 2016, 250). If you 
do not have a car (or dependable transport), you will likely face challenges given the car-centric nature of U.S. city and town planning. Living on-campus might not be the optimal plan for your first year, but it may affect your chances of persevering in your graduate program, especially if it enables you to build close relationships with your peers.

As soon as you get accepted into the graduate program, apply early for on-campus housing and plan your finances - paying rent from your monthly stipend or fellowship or savings will allow you to know how much money you are left with each month. It will take some to adjust as rent can be expensive in the U.S. Create a chart with monthly expenses for food, rent, and miscellaneous costs as this will help to keep track of your expenses. If you want to live off-campus, consider your daily commute to campus, and research how to sign a lease for an apartment. ${ }^{1}$ Additionally, you should consider the local culture that you are intending to move into and whether you would likely feel a sense of belonging. Some communities may oppose what they perceive to be "outsiders," even if you are only a student, and this could take a toll on your wellbeing. At the same time, if you come from a more traditional culture, U.S. campuses can be liberating. For instance, female graduate students at liberal universities can experience open discussions about sex, sexuality, gender, and abortion rights both inside and outside the classroom. This can be life-changing, not just for you as a woman, but also a value you can take home to discuss these taboo topics.

\section{Language advice}

Language courses can be useful, but some may perceive them as a form of othering or marginalization (Peters and Anderson 2021; Sharma 2020). Nonetheless, learning to communicate clearly is critical, including subscribing to political science norms that are expected for publishing in journals in the U.S. Some universities assume prospective students are proficient in academic writing, thus you should practice writing in advance, learn to share your own writing, and peer-review colleagues' work. Do not hesitate to utilize English proof-reading or writing centers on campus (should you need them) that will assist you with your course paper or manuscript - these services are often found in a university's library. They can guide you through the challenges of how to use the "Oxford comma," and cite and reference different sources of literature or material, among other things.

\section{Cultural norms in education}

International graduate students in the U.S. can encounter cultural shocks. The focus is often on international students adapting to the U.S. (Wang and Freed 2021). Nevertheless, there is need for adaptation on both sides. For international graduate students in political science - speak up! It can be challenging to adapt to the direct and "blunt" way many U.S. citizens communicate, especially if you are from a culture that places value on being reserved or passive with your opinion (Ma and GarciaMurillo 2018, 270). Learning to speak up and share your critical opinion about political science texts in your courses is an essential component of the U.S. graduate system. Undoubtedly, learning to communicate your thoughts coherently and effectively will take time and is a learned skill. If you are especially struggling, speak with your adviser and peers.

\section{Teaching}

Discrepancies in teaching style across different cultures can create difficulties for international graduate students who are teaching assistants or instructors of record. For instance, research (Wang 2021) shows that international students more familiar with lecture-based and less

\footnotetext{
${ }^{1}$ https://www.apartments.com/

https://www.realtor.com/advice/rent/rental-faq-renting-a-home-coronavirus/

https://www.realtor.com/advice/rent/can-you-break-a-lease-because-of-covid/

https://realestate.usnews.com/real-estate/articles/things-renters-should-do-before-signing-a-lease
} 
participatory forms of education can lead to challenges in the American education system that is more focused on interaction. Additionally, entering a classroom of undergraduate students can be nerveracking, but it can also be a fantastic opportunity for personal and professional growth.

Teaching or being a teaching assistant (e.g., grading, attending lectures, holding weekly office hours, responding to student emails, and sometimes leading discussion sections/seminars) will provide adequate funding to cover living expenses. These positions are usually limited to 20 hours per week and can be nine-month contracts (leaving summer as a period of "unemployment"), but the 20 hours will vary from week-to-week - some weeks you will only attend lectures and hold office hours, and other weeks you will be grading assignments and exams. If you get to teach your own class or discussion section, talk to your older peers who have experience, talk to your adviser, and utilize resources on campus - for instance, the 'Teaching office' or 'Learning center' can guide you.

Moreover, you should be aware that, as a non-U.S. citizen, your authority may be challenged as an instructor or discussion section leader by undergraduate students. This is even more likely to be the case if you are female and/or not white. Students may mock or laugh at your accent. Nonetheless, be attentive in speaking with an accent and understand that U.S. education is often very interactionbased, in which students are expected to respond to questions posed in the classroom. In smaller classroom settings (e.g., discussion sections), undergraduate students may engage in groupwork, actively write on chalkboards or interactive electronic screens, or participate in in-class activities (Stegall 2021, 725). If, however, you experience racism or discrimination, you should contact your instructor and adviser for support and resources to manage these incidents.

Prepare for your classes in advance by talking to your instructor (if you are a teaching assistant) or adviser. Consider what the appropriate student-assistant relationship looks like; how to report misconduct and plagiarism; if there is a dress code; and, most importantly, what your instructor expects of you in their lectures and what deadlines they have for grading (Stegall 2021, 732). Sometimes, undergraduate students will ask about your perspective on U.S. culture or political system, and while you can share your honest views, you should be respectful. You may also find that undergraduate students address you by your first name or, despite your request to be called by your first name, they may insist on referring to you as 'Professor' or using your surname.

Furthermore, consider visiting other (U.S. citizen) colleague's classes and see how they lead their classroom and how they communicate. Request multiple syllabi from colleagues and see how they present the material. In your first session, you can always tell students about yourself - who are you and where you come from. This is also a good opportunity to engage U.S. citizens about comparative political systems but be appropriate with what you teach to ensure it reflects the syllabus and meets students' expectations.

\section{Job market and the PhD}

For post-candidacy students, your greatest concern - beside your dissertation - will be navigating the political science job market. If you wish to work in the U.S. after completing your $\mathrm{PhD}$, you will need to begin applying for jobs one year in advance and, if you do not secure a job by the time you graduate, you could take advantage of optional practical training (OPT) that will enable you to stay in the U.S. for up to one additional year to seek employment. In the U.S., most political science jobs are posted in fall and will be hiring for fall next year. Closer to December, post-doctoral opportunities will begin to emerge and then, in spring, you can expect short-term, contractual roles (e.g., adjunct professors, visiting scholars). For OPT, you must apply for it in advance of graduating, so consult your office of international students to navigate this process. In the U.S., there are no federal quotas or limitations on non-profit organizations - which include most accredited U.S. universities and colleges - hiring non-U.S. citizens. If you pursue an academic career in the U.S., the Americanist field is, by far, the dominant field compared to others (e.g., Comparative Politics and 
International Relations). For methodology - which, for some universities, constitutes a field itself quantitative skills are almost always in demand. Unfortunately, this leaves fewer opportunities for those who specialize in qualitative methods, but there are still positions available. Generally, the academic job market is very competitive, so you must take this into consideration.

If you opt for the non-academic path, you will be subject to federal quotas on H1-B visas and, in most cases, only large companies will be willing to sponsor you as this process often leads the company to incur costs to hire you as a non-U.S. citizen. These visas are for temporary workers usually for three years and the possibility of it being extended for up to six years. In terms of nonacademic jobs related to political science, you may want to consider a career in consulting, planning, public policy, research centers, thinktanks, international organizations, and philanthropic organizations. Remember that, as a non-U.S. citizen, you will also be restricted from working for most local, state, and especially federal government organizations.

\section{References}

Arafeh, Alia K. 2020. "Insights into Saudi Female International Students." Journal of International Students 10(4): 1087-1102. doi: 10.32674/jis.v10i3.1111

Filonova, Irina., and Paola Barriga. 2020. "Coming to America." Inside Higher Ed [website], October 29, 2021. https://www.insidehighered.com/advice/2020/10/12/advice-international-graduate-studentswho-come-study-us-opinion.

Gautam, Chetanath., Charles L. Lowery., Chance Mays., and Dayan Durant. 2016. "Challenges for Global Learners: A Qualitative Study of the Concerns and Difficulties of International Students." Journal of International Students 6(2): 501-526. doi: https://doi.org/10.32674/jis.v6i2.368

Haverila, Matti J., Kai Haverila., and Caitlin McLaughlin. 2020. "Variables Affecting the Retention Intentions of Students in Higher Education Institutions." Journal of International Students 10(2): 358-82. doi: 10.32674/jis.v10i2.1849

Krsmanovic, Masha. 2021. "The Synthesis and Future Directions of Empirical Research on International Students in the United States." Journal of International Students 11(1): 1-23. doi: https://doi.org/10.32674/jis.v11i1.1955

Ma, Junqian. 2020. "Supporting Practices to Break Chinese International Students' Language Barriers." Journal of International Students 10(1): 84-105. doi: https://doi.org/10.32674/jis.v10i1.773

Ma, Yingyi., and Martha A. Garcia-Murillo. 2018. Understanding International Students from Asia in American Universities: Learning and Living Globalization. Cham, Switzerland: Springer.

Peters, Bethany, and Michael E. Anderson. 2021. "Supporting Non-Native English Speakers at the University." Journal of International Students 11(1): 103-21. doi:

https://doi.org/10.32674/jis.v11i1.1200

Sharma, Emily. 2020. "Writing Support for International Graduate Students." Journal of International Students 10(1): 220-22. doi: https://doi.org/10.32674/jis.v10i1.1013

Stegall, Jennifer. 2021. "Peaks and Valleys: The Lived Experiences of International Students Within an English Immersion Program Using the Integrated Skills Approach.” Journal of International Students 11(3): 723-741. doi: 10.32674/jis.v11i3.2395

Wang, Xinxin, and Rebekah Freed. 2021. "A Bourdieusian Analysis of the Sociocultural Capital of Chinese International Graduate Students in the United States." Journal of International Students 11(1): 41-59. doi: https://doi.org/10.32674/jis.v11i1.952 